\title{
The effects of lateral hypothalamic or septal lesions on cholinergically elicited drinking*
}

\author{
ROY E. PARKS, Southern Illinois University, Carbondale, Ill. 62901 \\ GER ALD W. STEIN, Southern Oregon College, Ashland, Oreg. 97520 \\ and
}

ROBERT A. LEVITT, Southern Illinois University, Carbondale, III. 62901

Bilateral lesions of the lateral hypothalamus completely and permanently suppressed the drinking elicited by an injection of carbachol into the lateral septal nucleus. Lateral septal lesions suppressed drinking to carbachol injection into the lateral hypothalamus $30 \mathrm{~min}$ following lesioning, but the carbachol-elicited drinking had recovered 5 days following lesioning.

Grossman (1960) reported that the introduction of a cholinergic substance into the perifornical lateral hypothalamus induced drinking in sated rats. This initial finding has been extended to include a number of other limbic-system structures (Fisher \& Coury, 1962). The diffuse distribution of this substrate has led to the proposal of a "drinking circuit" underlying the thirst drive (Fisher \& Coury, 1964; Miller, 1965). Recent evidence that anticholinergic treatment of any part of the circuit suppresses drinking to carbachol at any other part has led to the hypothesis that the entire circuit must be functional in order for drinking to carbachol to occur (Levitt \& Fisher, 1966).

Bilateral ablation of the lateral hypothalamic area (LHA) causes aphagia and adipsia. The rat will recover from this syndrome if maintained by tube feeding. Bilateral lesions of other limbic-system sites do not have this effect (Anand \& Brobeck, 1951; Teitelbaum \& Epstein, 1962). Wolf \& Miller (1964) observed that bilateral hypothalamic lesions completely blocked drinking to carbachol at a third site in the preoptic area or posterior hypothalamus. Cholinergic drinking did not recover, even after normal drinking had been reestablished. However, one problem with interpreting this effect as resulting from ablation of a part of the cholinergic drinking circuit is that the lesioned sites were not tested for cholinergic drinking prior to lesioning. In the present study, the effect of bilateral LHA lesions on carbachol drinking in the lateral septal nucleus (LSN) was compared to the effect of LSN lesions on carbachol drinking in the LHA. All three sites in each animal were tested with carbachol prior to lesioning.

*This research was supported by NIMH Grant MH-14381 from the US Public Health Service.

\section{METHOD}

The Ss were adult male hooded rats of the Long-Evans strain that weighed approximately $300 \mathrm{~g}$ at the time of surgery. Animals were individually housed, with food and water available except during testing, when only water was available.

The Ss were divided into two groups of 10 Ss each. Each $\mathrm{S}$ had three hollow cannulae (23 ga; guide shafts) surgically implanted into the brain. One group had bilateral implants in the LHA and a third placed into the lateral septal nucleus (LSN). The second group received two bilateral implants in the LSN and a unilateral implant in the LHA.

Five days after surgery, testing was initiated at the unilateral site. Crystalline carbachol (2-3 micrograms) was tamped into the tip of a $30 \cdot \mathrm{ga}$ cannula and then lowered into the brain through the permanently implanted guide shaft. Water intake was recorded during the hour prior to and following the introduction of the chemical. Tests were performed at 2-day intervals, with the cannula lowered $0.5 \mathrm{~mm}$ on each trial until a positive score was obtained ( $S$ drank $3 \mathrm{ml}$ more during the hour following than prior to chemical injection). The lesion sites were then tested for drinking to carbachol.

Bilateral lesions, approximately $1.0 \mathrm{~mm}$ in diam, were made in either the LSN or LHA under $\mathrm{CO}_{2}$ anesthesia with a Grass RF lesion maker. Electrodes insulated except at the tip $(0.5 \mathrm{~mm})$ were used.

Food and water intake and body weight measures were recorded daily from 5 days prelesion until the animal was maintaining its body weight on lab chow and water postlesion. Animals that received LHA lesions were maintained by tube feeding of up to $15 \mathrm{cc}$ daily of Sustagen. In addition, Sustagen, sweetened water, and sweetened wet lab chow were always available to these Ss.

All Ss were tested $30 \mathrm{~min}, 5$ days, and 30 days postlesion, or until a positive drinking score was obtained. This procedure completed, the animals' brains were perfused, frozen sections were stained with cresyl violet, and lesion and implant sites were microscopically verified.

\section{RESULTS}

The sites to be lesioned in the LHA prior to lesioning were negative to carbachol, whereas all the other sites were positive (unilateral LHA stimulation sites were $1.25 \mathrm{~mm}$ more rostral than the sites lesioned in the LHA). The LHA-lesioned animals developed the typical LHA syndrome, but little change was noted in the intake and body weight measures for the LSN-lesioned Ss.

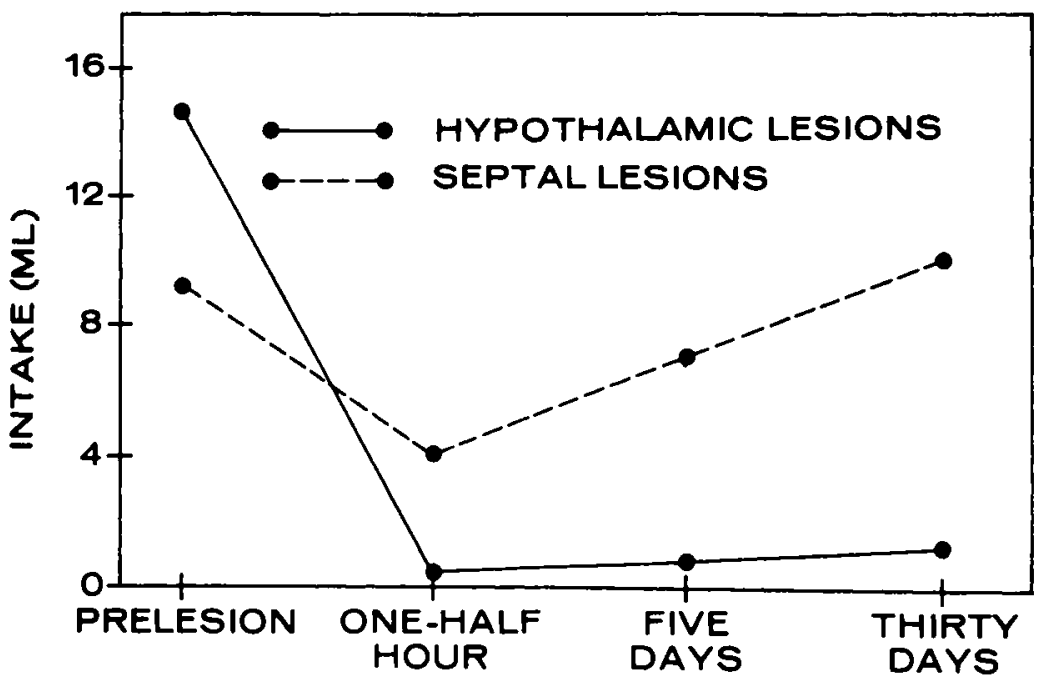

POSTLESION

Fig. 1. Average water intake for animals with hypothalamic or septal lesions. 
Figure 1 illustrates the major data f rom the experiment: Carbachol-drinking postlesion in the LHA lesioned group dropped to zero $1 / 2 \mathrm{~h}$ following lesioning and did not recover. Drinking to carbachol by the LSN-lesioned animals also dropped significantly $30-\mathrm{min}$ postlesion $(p<.05)$, but had recovered by 5 days postlesioning. Prelesion drinking scores were different between groups $(p<.05)$.

\section{DISCUSSION}

The findings of this study compare Eavorably with those reported by Wolf \& Miller (1964). It is interesting to note, however, that since none of the LHA-lesioned sites in the present study were cholinergically positive, the production of the LHA syndrome and the effect on carbachol drinking probably cannot be explained in terms of direct damage to the cholinergic circuit itself. How lesions in the LHA affect the circuit and block drinking remains unclear. Wolf and Miller suggest that the absence of peripheral stimuli in the central elicitation of thirst might account for its inability to recover; peripheral stimuli presumably play a role in the reappearance of natural thirst. The LHA sites lesioned in this study, although not included within the primary circuit, could possibly act in a manner similar to the ventral amygdala, also outside the circuit, but which exerts a facilitatory effect on it (Grossman, 1964).

The reduction of cholinergic drinking immediately following lesioning in the LSN was unexpected since no reduction was found after unilateral lesions of the LSN. I This effect may have been due to the additional trauma caused by the bijateral lesions or possibly to rerouting of neural functions to other circuit structures following bilateral lesions.

\section{REFERENCES}

ANAND, B. K., \& BROBECK, J. R. Hypothalamic control of food intake in cats and rats. Yaje Journal of Biology \& Medicine, 1951, 24, 123.

FISHER, A. E., COURY, J. N. Cholinergic tracing of a central neural circuit underlying the thirst drive. Science, $1962,138,691-693$.

FISHER, A. E., \& COURY, J. N. Chemical tracing of neural pathways mediating the thirst drive. In $M \quad J$, Wayner (Ed.), Thirst. New York: Pergamon Press, 1964. Pp. 515-529.

GROSSMAN, S. P. Eating or drinking elicited by direct adrenergic or cholinergic stimulation of the hy p ot halamus. Science, 1960,132 . 301-302.

GROSSMAN, S. P. Some neurochemical properties of the central regulation of thirst. In M. J. Wayner (Ed.), Thirst. New York: Pergamon Press, 1964. Pp. 487.511.

LEVITT, R. A., \& FISHER, A. E. Anticholinergic blockade of centrally induced thirst. Science, 1966, 154. 520-522.
MILLER, N. E. Chemical coding of behavior in the brain. Science, $1965,148$. 328-338.

TEITELBAUM, P.. \& EPSTEIN, A. N. The lateral hypothalamic syndrome: Recovery of feeding and drinking after lateral hypothalamic lesions. Psychological Review, 1962, 69, 74-90.

WOLF, G.. \& MILLER, N, E. Lateral hypothalamic lesions: Effects on drinking elicited by carbachol in preoptic area and posterior hypothalamus. Science, 1964. 143, 585-587.

NOTE

1. Stein, G. W., \& Levitt, R. A. Lesion effects on cholinergically elicited drinking in the rat. in preparation.

\title{
Sucrose concentration and the magnitude of approach in a conflict situation*
}

\author{
WAYNE L. WAAG, DOLORES M. TYLER, and JOE W. DARNALL† \\ Texas Tech University, Lubbock, Tex. 79409
}

Three groups, each containing eight rats on 23-h water deprivation, were trained in a straight alley runway. During acquisition, Group 1 received distilled water as a reinforcer, Group 2 a $4 \%$ sucrose solution, and Group 3 a $16 \%$ sucrose solution. Following acquisition, Ss received shock as they entered the goalbox. A derived measure of approach magnitude was obtained for 4 successive days of conflict testing. Significant differences were obtained on Day 1, indicating the magnitude of approach to be greater for those groups receiving a sugar solution as a reinforcer.

Miller (1959) has suggested that the magnitude of the approach component in an approach-avoidance conflict situation is a result of three major variables: drive strength, defined in terms of the number of hours of deprivation; the number of reinforced trials during acquisition of the approach response; and the amount of reinforcement presented on each training trial. Within the conflict paradigm, experimental evidence has been reported which supports the first two of these proposed relationships. Miller (1944) and Brown (1948) found that increases in the length of deprivation resulted in a heightening of the approach gradient. Kaufman \& Miller (1949) reported that the percentage of animals that reached the goal following shock was a function of the number of previous training trials reinforced with food. The effects of the third variable, amount of reinforcement, is the primary concern of this study. Since amount and quality of reinforcement generally have the same effect upon acquisition

*This research was supported by THEMIS Contract No. DAAD05-69-C-0102, between the U.S. Department of Defense and Texas Tech University, R. A. Dudek. Project Manager. The contents do not necessarily reflect the official opinion or policy of the Department of Defense or the Department of the Army. Reproduction is authorized for any purpose of the U.S. Government.

tNow at the University of Indiana Medical School. Indianapolis, Indiana. performance, it was hypothesized that increases in the quality of reinforcement, as determined by level of sucrose concentration, would result in an increase in magnitude of the approach component in an approach-avoidance conflict situation. SUBJECTS

The Ss were 30 male albino rats of the Holtzman strain. They were approximately 110 days old at the beginning of the experiment.

\section{APPARATUS}

The apparatus was a straight-alley runway, 6 in. wide and 6 in. high throughout, which contained an $8-\mathrm{ft}$ open runway and a 6-in. goalbox. The runway portion had a movable floor consisting of $166 \times 6 \mathrm{in}$. wooden blocks. Beneath each block was a microswitch, which, when depressed, activated a separate pen of a 20-channel Esterline Angus event recorder. The pens in the recorder were sequenced so that they corresponded to the sequence of blocks within the alley. In this manner, the exact position of the animal at any time could be determined. The goalbox floor was a grid constructed from brass welding rods spaced $1 / 2$ in. apart, through which a $200-\mathrm{V}$ shock could be delivered by a Gerbrands shock generator. The end of the goalbox was a translucent piece of Plexiglas through which a lick tube extended approximately 1 in. above the grid. Three different lick tube 